\title{
Development of the National Health Information Systems in Botswana: Pitfalls, Prospects and Lessons
}

\author{
Onalenna Seitio-Kgokgwe ${ }^{1 *}$, Robin D. C. Gauld ${ }^{2}$, Philip C. Hill ${ }^{2}$, Pauline Barnett ${ }^{3}$
}

1. Ministry of Health Gaborone, Botswana

2. Department of Preventive and Social Medicine, University of Otago School of Medicine, Dunedin, New Zealand

3. Health Sciences Centre, University of Canterbury, Christchurch, New Zealand

\begin{abstract}
Background: Studies evaluating development of health information systems in developing countries are limited. Most of the available studies are based on pilot projects or cross-sectional studies. We took a longitudinal approach to analysing the development of Botswana's health information systems.

Objectives: We aimed to: (i) trace the development of the national health information systems in Botswana (ii) identify pitfalls during development and prospects that could be maximized to strengthen the system; and (iii) draw lessons for Botswana and other countries working on establishing or improving their health information systems.

Methods: This article is based on data collected through document analysis and key informant interviews with policy makers, senior managers and staff of the Ministry of Health and senior officers from various stakeholder organizations.

Results: Lack of central coordination, weak leadership, weak policy and regulatory frameworks, and inadequate resources limited development of the national health information systems in Botswana. Lack of attention to issues of organizational structure is one of the major pitfalls.

Conclusion: The ongoing reorganization of the Ministry of Health provides opportunity to reposition the health information system function. The current efforts including development of the health information management policy and plan could enhance the health information management system.

Keywords: Disease outbreaks, electronic health records/classification, machine learning, natural language processing, public health informatics, public health surveillance/methods

Correspondence: oseitio@gmail.com

DOI: $10.5210 /$ ojphi.v7i2.5630

Copyright @2015 the author(s)

This is an Open Access article. Authors own copyright of their articles appearing in the Online Journal of Public Health Informatics. Readers may copy articles without permission of the copyright owner(s), as long as the author and OJPHI are acknowledged in the copy and the copy is used for educational, not-for-profit purposes
\end{abstract}

\section{Introduction}

Generation and effective use of health information is viewed as a central component of the stewardship function in a health system [1-3]. Health information is necessary to improve health outcomes, guide identification of health problems and population needs, inform planning and design of health interventions to address public health problems, guide decision making during 
allocation of scarce resources, and provide opportunity for monitoring and evaluating progress towards achievement of health goals [4-6].

The World Health Organization (WHO) views health information systems (HIS) as one of the building blocks of any health system [3]. Although the value of health information is acknowledged world-wide, most developing countries have weak and fragmented HIS [6]. African countries, in particular, lack effective systems that can ensure availability and use of health information to strengthen and support their health systems [7-9].

Having overall responsibility for health in many countries, ministries of health are charged with the responsibility for ensuring availability of health information. In 2008, African ministers of health made a formal commitment to strengthen their countries' HIS through the Algiers Declaration $[9,10]$. This is a daunting task considering widespread failure of HIS in developing countries $[11,12]$. Many factors influencing sustainability of information systems in general have been documented in the literature. These include organizational characteristics such as management support, and availability of infrastructure (including computing); and factors inherent in the implementation of information systems projects such as the extent of user involvement, and relationship with stakeholders including developers and donors [13]. In Ghana, infrastructure challenges, mainly internet connectivity and unstable power, limited development of HIS [14]. In Tanzania and Mozambique, lack of technical capacity, including personnel, and failure to involve end users were some of the challenges that affected development of HIS [12], while in Nigeria, relations and conflict of interests between the Ministry of Health (MOH) and the donor delayed implementation of a HIS project [15].

Studies evaluating development of HIS in developing countries are limited. In addition, most of the studies reported are based on pilot projects or cross-sectional studies focusing on short-term outcomes [11], limiting the opportunity to learn from past experiences. This article contributes to closing this gap. Drawing from a research study assessing the performance of the $\mathrm{MOH}$ in Botswana [16], we take a longitudinal approach to analyzing the development of Botswana's HIS based on data collected through document analysis and key informant interviews. The article seeks to: (i) trace the development of the national HIS in Botswana (ii) identify pitfalls during development and prospects that could be maximized to strengthen the system; and (iii) draw lessons for Botswana and other countries working on establishing or improving their HIS.

\section{Methodology}

\section{Setting}

Botswana is a middle income country with a population of 2 million [17] sparsely distributed across a land of about $582000 \mathrm{~km}^{2}$. More than $40 \%$ of the population is estimated to live in rural areas [17]. Health services in Botswana are delivered through the public and private health sectors. The public health sector is organized into different levels based on the complexity of services provided. At the lowest level are 810 mobile health stops, 340 health posts and 243 clinics [18]. There are 16 Primary Hospitals and seven District Hospitals, while three National Referral Hospitals represent the highest level of the system [18]. Before April 2010, the MOH was responsible for all public hospitals while the Ministry of Local Government was responsible for clinics, health posts and mobile stops. Since then all services were consolidated under the $\mathrm{MOH}$. The private health sector in Botswana is poorly understood $[19,20]$ and undocumented. 
Generally, it comprises not-for-profit and for-profit hospitals, clinics, pharmacies, laboratories and Medical Aid Schemes.

\section{Study design}

We adopted a case study approach [21] and used a mixed methods research design in assessing performance of the Botswana $\mathrm{MOH}$ [16]. The dominant methodology was qualitative using document analysis, key informants and focus group interviews. The quantitative arm comprised surveys for hospital managers and health workers [16]. Data were collected in 2009 through 2010. This article is based on data from the document analysis and key informant interviews.

\section{Framework}

The WHO/Health Metrics Network Framework and Standards for Country Health Information Systems (HMN Framework) [6] was adapted and used to guide the analysis. The Health Metrics Network (HMN) is a global partnership established in 2005 that focuses on strengthening the HIS of low-middle income countries [6]. The network developed the framework and an assessment tool for health information systems that are increasingly guiding countries in development, assessment and management of their HIS [22].

The HMN framework identifies six components of a functional HIS as HIS resources, indicators, data sources, data management, information products, and information use [6]. Drawing from these components we identified five assessment domains: structure for coordination and leadership of the national HIS; policy and regulatory framework for the HIS; infrastructure, financial and human resources to support the HIS; availability, adequacy and quality of health information; and health information use in planning, monitoring and evaluation of health services. A set of performance indicators was developed for each of the five assessment domains and used to guide the analysis (Table 1).

The importance of appropriate structures for coordination and leadership of national HIS has been well documented [9,23]. A well defined structure delineates the roles and responsibilities of the different players ensuring accountability and efficiency in the management of health information. The central coordination and leadership role is crucial in ensuring that activities of various players and organizations are coordinated to ensure integration and coherence of the system [9].

Table 1: Assessment domains and indicators

\begin{tabular}{|l|l|}
\hline Assessment domain & Indicator \\
\hline $\begin{array}{l}\text { Structure for coordination and leadership of } \\
\text { the national HIS }\end{array}$ & $\begin{array}{l}\text { i. Availability of a structure for coordinating } \\
\text { national HIS }\end{array}$ \\
\hline HIS policy and regulatory framework & $\begin{array}{l}\text { i. Availability of HIS policy } \\
\text { ii. Availability of HIS strategic plan } \\
\text { iil. Availability of HIS regulatory framework }\end{array}$ \\
\hline $\begin{array}{l}\text { HIS resources, financial and human } \\
\text { resources to support the health information } \\
\text { systems }\end{array}$ & $\begin{array}{l}\text { i. Availability and HIS infrastructure } \\
\text { ii. Availability of HIS human resources } \\
\text { iii. Availability of financial resources for HIS } \\
\text { information }\end{array}$ \\
\hline
\end{tabular}




\begin{tabular}{|l|l|l|}
\hline $\begin{array}{l}\text { Health information use in planning, } \\
\text { monitoring and evaluation of health } \\
\text { services }\end{array}$ & $\begin{array}{l}\text { Extent of health information use in } \\
\text { planning, monitoring and evaluation }\end{array}$ \\
\hline
\end{tabular}

Appropriate policies and legislation form the basis of a sound HIS [5]. Policies define priorities and provide a guiding framework within which all stakeholders operate. Legislation enhances access to data from all sources including the private and non-governmental health institutions [6]. Appropriate HIS resources such as infrastructure, finance and human resources enhances the system's capacity to collect, store, retrieve and analyse data, and disseminate information [6]. Health information is only valuable to health systems if it is of good quality, available and adequate. An effective HIS provides timely access to reliable data that meets the needs of different users including policy makers [6]. Effective use of health information in policy development, priority setting during planning and designing of health interventions, monitoring and evaluation of health services and programs enhances delivery of quality health services that contribute to improved health outcomes in an equitable and responsive manner [6].

While the indicators based on HMN framework [6] provide detailed and comprehensive assessments of HIS at national and sub national levels, the assessment in this article is at a more general level while its scope is limited to the public health sector activities at the $\mathrm{MOH}$.

\section{Data Collection}

Data were abstracted from published and unpublished documents including National Development Plans; $\mathrm{MOH}$ policies, strategic and annual performance plans, and consultancy reports; budget speeches and related reports from Government and other agencies; and research reports [16]. Websites of major organizations such as the WHO were explored. We also searched electronic databases such as PubMed, ScienceDirect, Ovid, Scopus, Web of Knowledge, ProQuest, and Google Scholar for published articles.

A total of 54 key informants were purposively selected and recruited through personal contact including telephone calls and emails based on the relevance of their positions to the issues under consideration. A snowballing technique was used to identify some of the informants, especially those who had retired from the public service. The participants comprised policy makers, senior managers and staff of the $\mathrm{MOH}(\mathrm{N}=40)$, including a total of nine retired employees who held key positions in the Ministry. Senior officers from various stakeholder organizations $(\mathrm{N}=14)$, including Ministry of Local Government, non-governmental, private and professional organizations were also interviewed. All interviews were audio taped and transcribed.

\section{Data Analysis}

Data from documents and transcripts were analyzed using content and thematic analysis respectively guided by Miles and Huberman's approach which consists of data reduction, data display and conclusion drawing/verification [24]. A deductive approach was adopted where the study indicators acted as the organizing framework [16]. 


\section{Results}

\section{Context}

Between 1997 and 2007, there were two major projects designed to improve the status of the HIS in Botswana. One of the projects was part of a larger initiative on strengthening health sector development through a collaborative effort between the Government of Botswana and the Government of Norway in what was commonly referred to as the Botswana/Norway Health Sector Agreement (BNHSA). This agreement ran from 1997 to 2003 [25]. The second project known as BEANISH (Building Europe Africa collaborative Network for applying Information Society Technologies in the Healthcare Sector), was a European Union funded project of the World Information Technology Forum (WITFOR). Among other things, this project focused on strengthening HIS in Africa in order to improve the quality of health care decisions [26]. It started in 2005 and ended in 2007. Due to their centrality to HIS development in Botswana, reference will be made to these projects throughout this analysis.

\section{Structure for Coordination and Leadership of the National Health Information Systems}

There are several key players in the management of health information in Botswana. The Health Statistics Unit is seconded from the Ministry of Finance and Development Planning, and based at the $\mathrm{MOH}$ headquarters. It is responsible for collection of data from all health facilities and reporting of national health statistics. The various disease control programs in the $\mathrm{MOH}$ based in the Department of Public Health collect individual program data for purposes of program monitoring and evaluation. The Department of Civil Registration in the Ministry of Labour and Home Affairs is responsible for the registration of births and deaths. The National AIDS Coordinating Agency has overall responsibility for HIV/AIDS related information. The Department of Information Technology in the Ministry of Transport and Communication coordinates and oversees the distribution and use of Information and Communication Technology (ICT) in government facilities.

The Health Statistics Unit (previously the Medical Statistics Unit) was established as early as 1978 [27]. This unit was charged with the responsibility for coordinating collection, collation, analysis and dissemination of health information to support delivery of health services. While this unit could have been the focus for development of the national HIS, it was limited by human resource capacity due to inability to retain appropriately qualified personnel [28].

In 1983, an organizational review of the MOH observed that the overall health information function was weak [29]. The 1984 organizational structure, a product of the 1983 review, however, did not establish a unit dedicated to central coordination of health information. Responsibilities for health information were given to both the Health Statistics Unit and the Department of Primary Health Care which comprised all the public health programs. There was lack of clarity on how the two structures related with their shared responsibility. With both structures collecting data from health facilities using different data collection tools, standards and procedures, poor coordination and related challenges such as duplication of efforts and poor quality of data were observed [30].

Concerted efforts to revamp the system were made in the late 1990s through the BNHSA (agreement between Botswana and Norway) which attempted to address the coordination issues by giving the Health Statistics Unit more responsibility to coordinate and carry out health 
information management activities [31]. Efforts were also made to establish a health information committee comprising representatives from the various stakeholder organizations including development partners such as WHO and UNICEF [32]. The impact of this project was, however, limited. Consequently the MOH's 2002 organizational review noted serious gaps in health information management:

The MOH lacks a comprehensive Health Management Information System (HMIS), which would provide timely and reliable information on the performance of the health sector. At this moment in time, the $\mathrm{MOH}$ only has scanty and fragmented information on the output of the health services...In consequence, 'burden of disease' assessments, and attempts to specify priorities...for the public, are absent [33].

Based on this observation, the Management Information Systems Division, comprising Health Statistics and Information Technology (IT) units, was established as an integral part of the Department of Policy Planning Monitoring and Evaluation (DPPME) [33] in a new organizational structure adopted in 2005. Among its responsibilities, this division was to establish, coordinate and maintain an efficient and effective national HIS; produce and disseminate national health statistics; provide informatics leadership and expertise; and build a sustainable and reliable IT infrastructure and electronic health systems in the Ministry and its facilities [34].

The DPPME also housed the Monitoring and Evaluation Division. The responsibilities of this division included establishing and coordinating national monitoring and evaluation systems, and developing strategies for monitoring and evaluation of health policies and interventions [34]. The separation of health information and monitoring and evaluation appeared to have created confusion in roles. Consequently these two functions were regarded as one by the $\mathrm{MOH}$ employees and often referred to as health information/monitoring and evaluation.

While it was generally understood that the Health Statistics Unit has overall responsibility for health statistics at a national level, its role in overall health information management and its relation to the $\mathrm{MOH}$ became increasingly blurred:

...the belief is that there are forms used to collect information, but this information is collected for the purposes of the Statistics Act, not for the purposes of the consumption of the Ministry. That is the big difference that people must be aware of. The Health Statistics Unit has its own mandate and the $\mathrm{MOH}$ has its own mandate...

A key limitation for the development of the coordinating structure for health information was human resource capacity. While DPPME as a whole suffered capacity challenges, this was particularly so for the health information function. Almost five years after the adoption of the 2005 organizational structure, the monitoring and evaluation division was non-functional as suggested by an interviewee:

...almost 3-4 years after restructuring, some of the divisions within some departments are non-functional...for example, the Division of Monitoring and Evaluation in the Department of Policy, Planning, 
Monitoring and Evaluation is non-functional because there are no 'bodies' there.

The Health Statistics Unit lacked the necessary expertise and other resources to meet its obligations. Consequently, different programs in the Ministry continued to develop and manage their own systems [35] to meet their needs:

The current limitation within the Health Statistics Unit is that they have backlog in as far as the information that they have got. You can imagine getting data 3 weeks later and you find that you have an outbreak that you could have addressed earlier had you known...Until we are confident that we have the necessary expertise at the central level to address these issues, then we need to have these parallel systems...

This lack of coordination also meant that the efforts of other stakeholders in information management are poorly coordinated with multiple data flows contributing to a fragmented and inefficient system.

\section{Health information Systems Policy and Regulatory Framework}

The national HIS has always operated within a very weak policy and regulatory framework characterized by absence of health information legislation, national policy and strategic plan. One of the BNHSA HIS project's early intents was to establish a national health information policy to guide development of the HIS in the country [36]. This initiative was abandoned because of lack of Ministry management support despite efforts made by different stakeholders [36,37].

However, a major achievement in policy development was made at the national level with the development and adoption of the national ICT policy in 2007 [38]. Through this policy, the government affirmed its stance of promoting the use of ICT as a driver of efficiency to promote the country's social, economic and cultural development. The policy outlined specific objectives, programs and projects for different sectors. For the health sector, an e-health program was identified with a number of initiatives including establishment of an e-health council to provide leadership and coordination of e-health projects, review and develop appropriate policies, legislation and standards, and identify infrastructure necessary to support effective electronic information management [38]. The e-health council was, however, not pursued and consequently the gap in the policy and regulatory framework continued to date [39]. In the absence of appropriate policies, the roles and responsibilities of the various players remain unclear, including that of the Health Statistics Unit and the MOH.

The lack of appropriate legislation contributes to the current challenges experienced in collecting data from private health institutions. Private hospitals provide very limited information while private practitioners and non-governmental organizations do not report any data [39]. Absence of standards or guidelines at a national level [35] still characterise the system.

The MOH does not have a national health information strategic plan. The absence of policy and strategic plan is reported to have played a major role in the uncoordinated development of the electronic systems at program levels using varying levels of technology and platforms. These are 
mainly supported by donor funding which influences what departments can do irrespective of other planned activities or the Ministry's overall strategy:

...departments that have donor funding are able to do other things...They will just write and tell you that this is what they are moving forward with because some donor is rushing in with a lot of money...

\section{Health Information Systems Resources}

\section{Infrastructure}

Development of information system infrastructure is coordinated at a national level by the Ministry of Transport and Communication as part of the broader government strategy to promote use of ICT in the public sector. While disparities in availability of infrastructure to support the HIS were previously reported [40], the government computerization strategy enhanced provision of infrastructure such as communication networks and computers. In 2009, the infrastructure was reported as generally adequate [39]. Functioning computers and some communication systems such as telephones, email/internet services were widely available [39].

In line with the national ICT policy, the $\mathrm{MOH}$ made considerable strides in promoting the use of ICT in health care. In the absence of HIS strategic plan, this has created a myriad of standalone systems with limited interoperability. Some of the existing systems include the Integrated Patient Management System initiated in 2003 and currently implemented in a few hospitals and clinics, Patient Information Management System dedicated to management of patients on antiretroviral treatment and Cancer and TB Registration Systems [39]. Other systems for various functions of the Ministry including drug procurement and management, and health professions registration also exist. While these are notable achievements, the main challenge is the integration and management of data from all these systems [35].

In the past, the BNHSA project attempted to improve the system's capacity to integrate and manage information through software called Health-net [36,37]. This software was reportedly installed in most of the health districts that by the end of the project were found to have essential infrastructure to support it. However, the system was reported not to be effectively utilized because of lack of appreciation, commitment and ownership [37]. Within two years of the end of the BNHSA project, the BEANISH project aimed to address the issues of data fragmentation through a data warehousing system based in the health districts-District Health Information System (DHIS), with overall coordination at the Ministry level [41]. The DHIS was to use open source software that was to allow each program to maintain its own data set while providing for integration. By the end of the project, the DHIS was reported to have been piloted in four districts. The DHIS, however, fell off the Ministry's priorities until National Development Plan 10. This plan emphasized the need for health information, and has identified rolling out the DHIS and integration of the different information systems as some of the key activities [42]. The DHIS remains distant to participants from the districts, while it is a window of hope for some participants at the Ministry headquarters:

The DHIS as far as I am concerned is still a concept. Yes they have met and done all their IT things to come up with that...but nobody can give you anything tangible... 
DHIS can be used, it is a good system, it has been used in other countries such as South Africa, but you need to build the structures and you need to integrate these into the business rules...

\section{Financial Resources}

Although the $\mathrm{MOH}$ identified the need for health information as one of the key priorities during National Development Plan 6 and National Development Plan $7[43,44]$ the budget to support HIS development was not delineated. A breakthrough in financial support came as part of the BNHSA project that established a line budget that supported development of the HIS $[45,46]$. Although the intention was for the MOH to carry over financial support of the overall HIS development [47], the Ministry's budget over the years has been dedicated to building the necessary ICT infrastructure in public hospitals [48-50] with limited focus on the overall HIS. Although the National Development Plan 10 has identified the need for health information, emphasis is still on IT infrastructure where participants noted some growth in budget allocations:

We have seen quite some growth in terms of the budget that is set up for NDP10 so that we can have all the basic infrastructure in place...even though it is insignificant if you look at the whole Ministry budget.

\section{Human Resources}

The BNHSA project made significant efforts to build human resource capacity for health information management $[36,51]$ particularly at the central level. Several officers were trained on different aspects of health information management activities [37,51]. However, high staff turnover undermined the achievements made in this area and limited development of the entire system. Although the $\mathrm{MOH}$ acknowledged the need for people trained in health information management in its National Health Manpower Plan 1997-2003 [52], challenges with external training and recruitment continued to undermine the system's human resource capacity. The lack of personnel trained in health information management and related fields continued to be felt at all levels of the system [35].

\section{Availability, Adequacy and Quality of Health Information}

Failure to produce timely annual statistics reports; poor data quality related to fragmentation of data collection using different tools, procedures and standards; inadequate data analysis; limited, unsystematic and non-institutionalized feedback from the Ministry to the districts; and generally poor information dissemination are some of the persistent challenges that have characterized the Botswana HIS over the years [28,30,35]. Participants from the districts were particularly concerned with the lack of feedback from the Ministry headquarters:

Information generated is meant to be able to serve the user which is the district or the facility itself. They should be able to get feedback to take corrective measures...but there is a feed forward system because we all have to submit reports to the $\mathrm{MOH}$ but there is no feedback mechanism to ensure this information is shared...

I am sitting here as a coordinator of health services. I have very little information...If you ask me "what is the health of your nation 
in the district?” I would not be able to tell you....actually I go to Gaborone in May and November now to see how my district is performing because the reports are going directly there.

Although huge amounts of data are reported as collected by the various agencies in the health sector, lack of policies guiding access to data contributes to the perceived lack of data or access to it by stakeholders:

...if you look at (name) program, huge chunks of data! But there is paranoia on who should access information and who should analyze it and publish on it. But they are so preoccupied with day to day service delivery. Nobody will have the opportunity or even the time to dip in and look at those data and analyze those data sets...

The BNHSA project attempted to address data fragmentation and quality issues through development of a national set of core indicators to promote coordination and efficiency of data collection [32]. While it was reported that a set of 44 indicators measuring morbidity and mortality for common health problems was developed through consultation with relevant stakeholders [32], there is no evidence that these indicators were accepted and used as intended, as different programs continue to collect their own data using different tools.

\section{Health information use}

Limited data use has been reported due to various reasons including lack of timeliness in production of reports, analysis, interpretation, and dissemination [30,32,39]. Fragmentation of data and challenges with access discourages potential data users:

Our data is scattered. Very often when we are supposed to prepare reports, it is not readily available in one place. You will find that some information is somewhere in files, some information is in a computer somewhere... but not all the information is such that you can easily access it...it is extremely fragmented and much of it is paper based.

Past efforts made by the BNHSA and BEANISH projects had limited impact on making health information available and effectively used by decision makers. Both projects made unsuccessful efforts to strengthen the national HIS technical capacity to manage information through the Health-net and DHIS which could facilitate data harmonization and the creation of the reports to support decision makers.

While fragmentation and inefficient HIS contributes to poor utilization of information, lack of appreciation of the important role played by health information in managing health services on the part of health managers is also seen to be a major influence:

...I have never heard anybody looking for specific information for planning. They just want numbers to put in tables or when they are going to present somewhere. As to how the information is used, how we are using it for planning, nothing hardly happens... 
However, in the area of program management, several participants acknowledged that disease specific programs in the Department of Public Health and Department of HIV/AIDS and Care adequately use their program specific information to monitor program performance and effectively use such information to improve program designs and implementation.

\section{Discussion, pitfalls and prospects}

Drawing from the WHO/Health Metrics Network Framework and Standards for Country Health Information Systems (HMN Framework), we identified five assessment areas and developed a set of performance indicators that we used as a guide in tracing the development of Botswana's national HIS. We identified challenges, pitfalls and opportunities that could provide learning experiences for Botswana and other countries in the process of developing their HIS.

\section{Coordination and leadership}

One of the key challenges for Botswana's health information is the weak capacity at the national level for effective coordination and management of the HIS. Issues related to structure had a significant impact on development of the HIS coordination function. Although the Health Statistics Unit has always existed in the $\mathrm{MOH}$, albeit as a seconded unit from the Ministry of Finance and Development Planning, it was poorly integrated with the $\mathrm{MOH}$ structures, and lacked leadership support and ownership. As a result, the unit suffered capacity challenges limiting its ability to undertake coordination and leadership responsibilities for health information.

The need for a central unit in the $\mathrm{MOH}$ responsible for health information management is considered a critical success factor in development and management of an efficient HIS [6,9]. While significant efforts were made to address the issue of health information coordination in the MOH 2005 organizational structure, there were several pitfalls in this structure. During the design of the structure, the Health Statistics Unit was combined with the IT Unit to form the Management of Information Systems Division. While the role of technology in enhancing HIS is acknowledged worldwide [12,53], the mandates of the two units are different. The consequence of this structure was the equating of HIS with IT systems. Investment and development therefore focused on providing general ICT infrastructure including the various electronic systems with limited focus on the overall national HIS. These units have since separated with IT moved to the Department of Corporate Services, while the Health Statistics Unit remained in the DPPME.

Poorly defined roles and responsibilities was another challenge in the structure. In addition to the Management of Information Systems Division, the Monitoring and Evaluation Division was also charged with some health information responsibilities. This lack of clarity of roles between the two divisions created confusion. Well delineated roles and functions prevent duplications and fragmentation of work [54]. Lack of coherence and integration of function [2,54] was also a challenge. Although the Health Statistics Unit and Monitoring and Evaluation division are in the same department these exist as distinct entities with poor linkages creating inefficiencies.

Lack of effective national leadership for health information management in Botswana was another chronic challenge. Over the years, projects designed to strengthen the HIS could not achieve their goals because of leadership challenges, lack of commitment, support and guidance. The BNHSA project, for example, was not able to facilitate development of a national HIS policy. Similarly the BEANISH project had minimal impact on addressing the fragmented nature 
of the HIS. Effective leadership at senior management level is essential for placing HIS issues in the policy agenda, advocating or motivating for the use of the systems, negotiating for resources and promoting effective use of the system outputs $[13,55,56]$.

The MOH started another round of organizational review in 2012. The new organizational structure is going through the approval processes. This reorganization provides an opportunity for the Ministry to reposition the health information management function, set up appropriate structures, clearly define roles and responsibilities, and establish well-defined linkages with other related functions. The new structure also provides an opportunity to address the human resource needs for the health information function through recruitment or retraining. Both technical and leadership competencies are critical for the success of the system.

\section{Policy and regulatory framework for health information systems}

The absence of HIS policies and legislation in Botswana contributed to poor availability and low quality information. Since provision of health information is not mandatory, the country receives very little information from the private sector and nongovernmental organizations, which affects the completeness and hence undermines the accuracy of the information. Poor reporting from the private sector is, however, not unique to Botswana. Countries such as Uganda, Zambia and Malawi [57-59] share similar problems although they are due to inadequate enforcement of regulations as opposed to lack of regulations since their policy frameworks are reportedly well established. The lack of policies defining responsibilities and guiding the actions of the different actors creates inefficiencies which have negative impact on the overall HIS. Lack of a coherent national strategy for HIS contributed to poor coordination of activities promoting duplication of efforts and poor investment.

In 2011, the MOH revised its 1995 national health policy. The revised policy identified HIS as one of the priorities and, hence, aimed to establish a coordination mechanism that will facilitate data management and use [60]. Subsequent to review of the national health policy, the Ministry developed a National Health Service plan [61] to facilitate its implementation. This plan outlines the strategic plan for health information systems/monitoring and evaluation. Strategic actions in this plan include defining coordination structures and roles and responsibilities of key actors; identifying set of core indicators; and strengthening data use. Consequently, in 2013, the Monitoring and Evaluation Division facilitated development of the data management policy and monitoring and evaluation plan which are both awaiting further consultation and approval. Although these are promising developments, there is need to consider the challenges that often bedevil policy implementation such as failure to adequately plan for implementation, mobilize the necessary resources [62,63], and to provide effective leadership for the implementation process. The HIS policy and plan will contribute significantly to HIS development if they are implemented.

\section{Resources for Health Information Systems}

As in other developing countries [12,14,15], the HIS in Botswana has suffered from inadequate resources. The $\mathrm{MOH}$ does not have a line budget to support HIS activities. The system also lacked appropriately qualified personnel at all levels for the various functions spanning from data collection to data analysis and promotion of effective use of health information. Lack of training in health information management for personnel at different levels of the health system can have a significant impact on the availability and quality of data and the extent to which information 
will be used for planning and decision making [64]. An opportunity to address the human resource needs for the health information function is provided by the local tertiary education sector with some training institution having established training in health informatics and monitoring and evaluation. The merit will be on $\mathrm{MOH}$ to use these programs to retrain its staff.

\section{Availability, quality of health information}

The chronic lack of central coordination of the HIS in Botswana has perpetuated the development of an array of disjointed sub-systems contributing to fragmentation and poor integration of data. Consequently, the system is inundated with data from various sources, for example, disease specific programs, Health Statistics Unit and several facility-based electronic systems. The importance of a minimum essential data set to reduce redundancy and promote efficiency in data collection and reporting is considered one of the key factors in developing an effective HIS [65]. While some countries have benefited from establishing essential data sets of indicators to monitor the overall health system [66], Botswana has not been successful in this regard. The collection of data for multiple programs using multiple tools undermines the quality of data and also overburden health care providers [64,67].

As part of the overall Government ICT strategy, the $\mathrm{MOH}$ is working on rationalizing the various existing electronic systems. This will call for termination or integration of some systems. Other efforts include strengthening the data warehouse at the $\mathrm{MOH}$ and establishing a minimum set of core indicators, which are some of the tenets of the draft national monitoring and evaluation policy and plan. It is, however, important to note that experience from other countries illustrates that attempts at integration of fragmented HIS present significant challenges and is difficult to achieve $[22,55,68]$. Sahay, Monteiro et al based on their experience working with the health information systems in India, argue that the integration of HIS should not be viewed only as a technological undertaking, but should also consider the needs and interests of other stakeholders including program managers and their donor agencies [68]. This view is well supported by studies on development of health information systems in other countries [69].

\section{Data use}

As is the case in many countries [64,67], the fragmented HIS and lack of effective coordination has limited availability of data for planning, decision making and overall support of health system development in Botswana. Lack of timeliness in production of annual health statistics reports denies planners access to evidence. Poor feedback or dissemination of information denies the health districts and local facilities opportunities to use their health information to improve delivery of services. While there might be challenges in the system's capacity to analyze data related to human and technological capacity [4], the lack of policies to guide access to information plays a key role in denying other stakeholders such as researchers the opportunity to effectively use health information for the greater good of the public [70]. Countries developing their HIS are implored to address the issues of health information uses at the design phases of their HIS to ensure equity of access and promote effective and resourceful use of health information [70].

In an attempt to improve health information management and enhance data use, the Monitoring and Evaluation Division is promoting the use of DHIS. Through this system all programs can enter their data, and produce basic reports at user level. These data will also be available real time to program managers and other data users at the Ministry level where it could be aggregated 
at district and national levels. The data management policy, which waits management approval, aims to establish data sharing mechanisms to facilitate access to health information. The merit will be timely approval and implementation of this policy.

\section{Lessons for Botswana and other developing countries establishing HIS}

In taking an evolutionary approach in analyzing development of the HIS in Botswana, some key lessons emerge that Botswana and other developing countries can learn as they develop their systems. The need for a structure dedicated to coordination of HIS is vital. Roles, responsibilities, and relationships between various structures with health information responsibilities must be clearly defined. The relationship of the Health Statistics Unit and the $\mathrm{MOH}$ health information unit, in particular, needs to be defined and if possible guided by some form of policy instruments. The lack of HIS coordinating structure and overlapping roles and responsibilities has undermined development of HIS in Botswana. Technical and leadership competencies in the health information systems coordinating structure is an essential ingredient to HIS success. Able leadership could provide strategic direction for the HIS function, and mobilize resources needed to support the development and functioning of the HIS. Finally, while IT is essential as an enabler of effective HIS, it is important to recognize that the two are not synonymous, and hence investment in both should occur concurrently to have a functional system that could provide health information in a timely manner. Botswana invested significantly in IT infrastructure, while the overall HIS was under funded. Consequently the HIS remains poorly developed.

\section{Conclusion}

In this article, we traced the development of the HIS in Botswana, identifying pitfalls and prospects in this historical journey and drew important lessons for those working in HIS development. Overall, Botswana struggled to establish a functional HIS over the years. Significant challenges existed in all aspects of the system undermining progress. Chronic challenges such as lack of central coordination, weak leadership, poor policy and regulatory frameworks, and inadequate resources were observed. Some pitfalls included lack of attention to organizational structure designs creating duplication of roles, and poor integration of units and functions. Opportunities are provided by the ongoing reorganization of the $\mathrm{MOH}$ through which the health information function can be repositioned. Ongoing efforts to establish the policy framework for health information management could be optimized. Training of health information professionals in local institutions can strengthen the human resource capacity of the national HIS.

\section{Limitations}

We adapted and used the HMN Framework and Standards for Country Health Information Systems to guide assessment of the Botswana HIS. While this framework has been used in several countries to evaluate national HIS, its use in research is still limited. There is need for more studies using this framework to build evidence on its utility in HIS research. 


\section{Acknowledgements}

The authors would like to thank the Ministry of Health-Botswana management and staff for the support, and study participants for their willingness. The research reported in this article was primarily funded by a University of Otago Scholarship, for which the first author is grateful

\section{Ethical issues}

This study was approved by the University of Otago Ethics Committee and the Health Research and Development Committee in the $\mathrm{MOH}$, Botswana

\section{Competing Interest}

The authors have no competing interests

\section{Financial Disclosure}

No Financial Disclosure

\section{References}

1. WHO. The World Health Report 2000: Health systems: Improving performance. Geneva: World Health Organization. 2000.

2. Travis P, Egger D, Davies P, Mechbal A. Towards better stewardship: concepts and critical issues. Geneva: World Health Organization. 2002.

3. WHO. Everybody's business: Strengthening health systems to improve health outcomes: WHO's framework for action. Geneva. 2007.

4. AbouZahr C, Boerma T. 2005. Health information systems: the foundations of public health. Bull World Health Organ. 83(8). PubMed

5. Stansfield S, Walsh J, Prata N, Evans T. Information to improve decision making for health. In: Jamison D, Breman J, Measham A, Alleyne G, Claeson M, Evans DB, et al., editors. Disease control priorities in developing countries. 2 ed. Washington DC: World Bank; 2006.

6. WHO. Health Metrics Network: Framework and standards for country health information systems $2^{\text {nd }}$ ed.: World Health Organization. 2008.

7. Kebede D, Zielinski C, Mbondji PE, Sanou I, Asamoah-Odei E, A, Soumbey-Alley E, W, et al. Improving the availability, quality and use of health information, research evidence and knowledge to strengthen health systems. The African Health Monitor. 2010;AprilJune(12):53-64.

8. Kimaro HC, Mengiste SA, Aanestad M. 2008. Redesigning health information systems in developing countries: The need for flexibility and distributed control. Public Adm Dev. 28, 18-29. http://dx.doi.org/10.1002/pad.473

9. WHO. The Algiers Declaration. Brazzaville: WHO Regional Office for Africa.2009.

10. Lusamba-Dikassa P, Kebede D, Sanou I, Asamoah-Odei E, A, Soumbey-Alley E, W, Mbondji PE, et al. The background and significance of the Algiers Declaration and the Framework for its implementation. The African Health Monitor. 2010;April-June(12):6-9. 
11. Heeks R. 2006. Health information systems: Failure, success and improvisation. Int J Med Inform. 75, 125-37. PubMed http://dx.doi.org/10.1016/j.ijmedinf.2005.07.024

12. Kimaro HC, Nhampossa JL. 2005. Analyzing the problem of unsaustainable health information systems in less-developed economies: Case studies from Tanzania and Mozambique. Inf Technol Dev. 11(3), 273-98. http://dx.doi.org/10.1002/itdj.20016

13. Petter S, William D, McLean E. 2013. Information systems sucess: The quest for the independent variables. J Manage Inf Syst. 29(4), 7-61. http://dx.doi.org/10.2753/MIS0742$\underline{1222290401}$

14. Achampong E. 2012. The state of information and communication technology and health informatics in Ghana. Online $J$ Public Health Inform. 4(2), 1-12. PubMed http://dx.doi.org/10.5210/ojphi.v4i2.4191

15. Asangansi I. 2012. understanding HMIS implementation in a developing country Ministry of Health context: an institutional logic perpective. Online J Public Health Inform. 4(3). PubMed http://dx.doi.org/10.5210/ojphi.v4i3.4302

16. Seitio-Kgokgwe O. Organizational Structure of the Botswana Ministry of Health: Impact on Performance. Dunedin: University of Otago; 2012.

17. CSO. Population and housing census report. Gaborone Central Statistics Office2012.

18. CSO. Health facility by type and number of beds 1998-2006. Gaborone: Central Statistics Office; 2009 [cited 2010 03/09]; Available from: http://www.cso.gov.bw

19. Møgedel S, Steen S. 1995. Health sector reforms and organizational issues at the local level: Lessons from selected African countries. J Int Dev. 7(3), 349-67. http://dx.doi.org/10.1002/jid.3380070304

20. Stewart S. Botswana. In: Fried B, Gaydos L, editors. World health systems: Challenges and perspectives. Washington D.C: Association of University Programs in Health Administration; 2002.

21. Yin RK. Case Study Research: Design and Methods. 3rd ed. London: Sage Publications; 2003.

22. Braa J, Hanseth O, Heywood A. 2007. Developing health information systems in developing countries: The flexible standards strategy. MIS Quartely. 31(Special Issue), 1-22.

23. WHO. Framework for the implementation of the Algiers Declaration on research for health in the African region. Brazzaville: WHO Regional Office for Africa. 2009.

24. Miles MB, Huberman AM. Qualitative data analysis 2nd ed. Thousands Oaks: Sage Publications; 1994.

25. MOH. Agreement between the Government of the Republic of Botswana and the Government of the Kingdom of Norway regarding institutional cooperation within the health sector. Gaborone: Ministry of Health 1985.

26. Hedberg C, Chandna O. Developing and implementing an integrated Health Information System (HIS) at district and national levels in Botswana: Project initiation document. Gaborone 2005. 
27. Annual Report MOH. Gaborone: Ministry of Health.1980.

28. $\mathrm{MOH}$. Health information system for effective utilization of PHC services and facilities in Botswana. Gaborone: Ministry of Health. 1986.

29. Directorate of Personnel. Report on ministerial organization review: Ministry of Health. Gaborone.1983.

30. MOH. Botswana health information system: Assessment and five year plan. Gaborone: Ministry of Health. 1997.

31. Otsweleng R. S, Eggen Ø. The health sector agreement between Botswana and Norway: Annual report 2002. Gaborone: Botswana. 2003.

32. Beleme G, Gjertsen F, Borgan J-K. Health indicators and health information system in Botswana Oslo: Statistics Norway. 2000.

33. $\mathrm{MOH}$. A review of the organizational structure of the $\mathrm{MOH}$ in Botswana: Final report Gaborone: Ministry of Health. 2002.

34. MOH. Republic of Botswana: Ministry of Health: Services. Gaborone: Ministry of Health; 2009 [cited 2009 02/11/2009].

35. MOH. National health service situational analysis report. Gaborone: Ministry of Health, 2009.

36. Olsen I. Theo, Moalosi G, Modirwa. The health sector agreement between Botswana and Norway: Annual report 1998. Gaborone: Ministry of Health. 1998.

37. Olsen I. Theo, Høivold E. The health sector agreement between Botswana and Norway: Annual report 1999. Gaborone: Ministry of Health.1999.

38. Government of Botswana. National information and communication technology policy. Gaborone: Ministry of Communication Science and Technology. 2007.

39. MOH. Situational analysis: Health information/monitoring \& evaluation within the health service delivery setup:2008. Gaborone. 2009.

40. Government of Botswana. Maitlamo Botswana's National ICT Policy Gaborone. 2005.

41. Chandna O. BEANISH Pilot Project Review Report Botswana v 0.1.doc (Draft). Gaborone: Ministry of Health. 2005.

42. MFDP. National Development Plan 10: 2009/2016 Volume 2. Gaborone: Ministry of Finance and Development Planning. 2009.

43. MFDP. National Development Plan 7:1991-97. Gaborone: Ministry of Finance and Development Planning. 1991.

44. MFDP. National Development Plan 6: 1985-1991. Gaborone, 1985.

45. MFDP. National Development Plan 8: 1997/98-2002/03. Gaborone: Ministry of Finance and Development Planning. 1997.

46. MOH. Statement by Minister of Health Hon. Joy Phumaphi to the Committee of Supply $13^{\text {th }}$ March 2001. Gaborone: Ministry of Health. 2001. 
47. MOH. Speech by the Minister of Health Hon. Joy Phumaphi to the Committee of Supply $12^{\text {th }}$ March 2003. Gaborone: Ministry of Health. 2003.

48. MOH. Ministry of Health recurrent and development budget proposal for the 2005/2006 financial year presented to the Committee of Supply by Honourable Minister S.D Tlou. Gaborone: Ministry of Health. 2005.

49. $\mathrm{MOH}$. Recurrent and development budget proposal for the 2006/7 presented to the Committee of Supply by Honourable Minister S.D Tlou $7^{\text {th }}-8^{\text {th }}$ March 2006. Gaborone: Ministry of Health. 2006.

50. MOH. Committee of Supply speech presented by Honourable S.D Tlou $7^{\text {th }}$ March 2007: 2007/2008 recurrent and development budget. Gaborone: Ministry of Health. 2007.

51. Kebakile S, Høivold E. The health sector agreement between Botswana and Norway: Annual report 2000. Gaborone: Ministry of Health. 2000.

52. MOH. National health manpower plan for Botswana 1997-2003. Gaborone: Ministry of Health. 2001.

53. Lucas H. 2008. Information communications technology for future health systems in developing countries. Soc Sci Med. 66(10), 2122-32. http://dx.doi.org/10.1016/j.socscimed.2008.01.033

54. Downey D. Designing dynamic organizations: A hands-on guide for leaders at all levels. New York: American Management Association International; 2001.

55. Chaulagai CN, Moyo CM, Koot J, Moyo HMB, Sambakunsi T, et al. 2005. Designing and implementation of a health management information system in Malawi: Issues, innovations and results. Health Policy Plan. 20(6), 375-84. http://dx.doi.org/10.1093/heapol/czi044

56. Kearns GS. 2007. How internal environment impact information systems project success. An invesigation of exploitative and explorative firms. J Comput Inf Syst. 48(1), 62-75.

57. $\mathrm{MOH}$. Assessment of the health information system in Uganda. Kampala: Ministry of Health. 2007.

58. MOH. Health information systems assessment report Lilongwe: Ministry of Health,2009.

59. MOH. Assessment of the health information system in Zambia. Lusaka: Ministry of Health. 2007.

60. MOH. National health policy: Towards a healthier Botswana. Gaborone,2012.

61. MOH. Integrated health service plan: A strategy for changing the health sector for a healthy Botswana 2010-2020. Gaborone. 2010.

62. Crosby BL. 1996. Policy implementation: The organizational challenge. World Dev. 24(9), 1403-15. http://dx.doi.org/10.1016/0305-750X(96)00050-2

63. Hogwood BW, Gunn LA. Policy analysis for the real world. Oxford: ELBS; 1984.

64. Nyamtema AS. 2010. Bridging the gaps in the health management information system in the context of a changing health sector. BMC Med Inform Decis Mak. 10(36). PubMed 
65. Murray CJL. 2007. Towards good practice for health statistics: lessons from the Millennium Development Goal health indicators. Lancet. 369(9564), 862-73. PubMed http://dx.doi.org/10.1016/S0140-6736(07)60415-2

66. Shaw V. 2005. Health information system reform in South Africa: developing an essential data set. Bull World Health Organ. 83(8), 632-36. PubMed

67. Garrib A, Stoop N, McKenzie A, Dlamin L, Govender T, et al. 2008. An evaluation of the District Health Information System in rural South Africa. S Afr Med J. 98(7), 549-52. PubMed

68. Sahay S, Monteiro E, Aanestad M. 2009. Toward a political perspective of integration in information systems research: The case of health information systems in India. Inf Technol Dev. 15(2), 83-94. http://dx.doi.org/10.1002/itdj.20119

69. Sæbøa JI, Kossia EK, Titlestada OH, Tohouria RR, Braaa J. 2011. Comparing strategies to integrate health information systems following a data warehouse approach in four countries. Information Technology for Development Special Issue. 17(1), 42-60. http://dx.doi.org/10.1080/02681102.2010.511702

70. McGrail K, Black C. 2005. Access to data in health information systems. Bull World Health Organ. 83(8). $\underline{\text { PubMed }}$ 